\title{
Os corpos em Nuno Ramos e Claire Denis - da Experiência Interior ao Resto
}

Diego Pereira Ferreira, Instituto de Letras, Universidade Estadual do Rio de Janeiro, Rio de Janeiro, RJ; E-mail: <ferreira.diego@globo.com>

\begin{abstract}
Resumo
O estudo pretende analisar as relações eróticas estabelecidas entre personagens e excrementos no ensaio literário Ó, de Nuno Ramos, e no filme Nenette e Boni, de Claire Denis. As figuras de linguagem do corpo "abandonado" - o suor, o sangue, o sêmem serão estudadas sob a perspectiva da noção de Resto da psicanálise: sintomas de que o discurso [o corpo] não se completa. 0 tema será norteado, portanto, pela ação dos personagens que se realizam na incompletude, na eterna busca de si próprios: existimos, afinal, para além dos limites do corpo, da pele? Como fio condutor na análise das obras supracitadas serão utilizados os conceitos de Erotismo e Experiência Interior, de Georges Bataille. A pesquisa evoca questionamentos presentes na filosofia contemporânea: o descentramento do sujeito e a dissolução do eu.
\end{abstract}

Palavras-chave: Erotismo, Experiência Interior, Resto, incompletude, corpo, sujeito.

Um corpo inconcebível diante de nós, em nós. E a consciência

- não menos inconcebível - enterrada atrás dos olhos e da pele. A massa de carne e ossos esculpida pela vida, e que nos guarda, nos assemelha e nos distingue: a marca da ausência na presença, da solidão no encontro.

No interior de si, uma paisagem se mantém à distância dos olhos alheios. Somos, afinal, inapreensíveis em nossa totalidade, apenas deixamos os sintomas de nossa existência transbordar em curtos movimentos de palavras, sons e gestos que desembocam na frágil consciência do outro.

Este corpo não é sequer uma cápsula que nos contenha, produz e se separa da linguagem, em uma animalidade que não encontra sítio na razão, pois nem mesmo o sentido é lugar fixo: parte sempre de um caos primitivo inordenável que marca 
sentido.

"O corpo" é onde se cede. "Contra-senso" não quer dizer aqui qualquer coisa como o absurdo, nem como sentido invertido e contorcido (não é em Lewis Carrol que tocaremos nos corpos); mas indica que há uma ausência de sentido, ou que se trate de um sentido que nenhuma figura de "sentido" jamais poderá abordar. Um sentido que faz sentido no lugar em que, para o sentido, existe um limite. Sentido mudo, fechado, autista: mas sem autos, justamente sem "si próprio". O autismo sem os autos do corpo, o que faz dele muitíssimo menos que um "sujeito", mas também algo extremamente diverso, um jacto, e não um subjectum, que é tão duro, tão intenso e inevitável, tão singular como um sujeito. (Nancy, 2000: 14)

Esse corpo sempre incompleto é, por conseguinte, o resto de si próprio: produz os próprios restos, deixa que uma parte de si o abandone, incorpora as tantas partículas que absorvem os poros, os alimentos que digere, enquanto sua, sangra, defeca, num vasto movimento que se quer constante: uma passagem, um rio: transfusão.

El cuerpo es tan fluido y gaseoso como sólido. Es gaseoso en el intercambio rítmico de la respiración; de las narinas a los bronquios, un incesante intercambio de lo impalpable con lo impalpable, la infraleve suspención en el más volátil estado de la sustancia (la naturaleza, la cosa, lo real). En el corazón de ese intercambio, es fluido, fluye de venas y arterias, circula por todos lados, impregna y embebe la carne, los tejidos. (Nancy, 2014: 21)

Um lugar de estranheza, o corpo é o elo necessário para se relacionar o ensaio literário Ó, de Nuno Ramos, e o filme Nenette et Boni, de Claire Denis, partindo do pressuposto que ambos, escritor e cineasta, estão debruçados sobre os recentes questionamentos filosóficos sobre o corpo. O diálogo intermidiático entre as obras se dá através do impácto estético dos questionamentos presentes na filosofia contemporânea.

Em ambas as obras, a noção de erotismo batailleana aparece relacionada à noção de resto, já que o erotismo é, de uma forma elogórica, o produtor de resto da subjetividade: perturba a ideia da consciência ser um sistema fechado e autônomo. 
É preciso, portanto, reconhecer que a vida não é só essa camada interior, circula também para fora, se abrindo ao mundo que existe fora dela, e que é de certa forma também sua parte. Há uma espécie de comunicação primitiva que ocorre, portanto, entre deslizamentos - na leitura, na conversa, no olhar -, e se estabelece com a fragilidade e delicadeza do ser errante, que associa sons e formas aos sentidos borrados numa memória irrefreável, insubstancial. O erotismo quer escancarar essa janela.

O resto é a imagem mais fiel do desnudamento, se, desta forma, pensarmos os dejetos como as matérias que questionam nosso lugar de existência. Aqui se abre a fenda que possibilita o contato entre o erotismo e o resto: os pedaços que destroem, em mim, o sentimento de pertencer a um sistema fechado. E como se o corpo desmoronasse, deslizando sobre a terra fétida do desapropriar-se, da náusea de descobrir-se incircundável, temos a imagem da consciência acompanhando o movimento de nossos corpos através do erotismo.

A ação decisiva é o desnudamento. A nudez se opõe ao estado fechado, isto é, ao estado de existência descontínua. É um estado de comunicação que revela a busca de uma continuidade possível do ser para além do voltar-se sobre si mesmo. Os corpos se abrem para a continuidade através desses canais secretos que nos dão o sentimento da obscenidade. A obscenidade significa a desordem que perturba um estado dos corpos que estão conformes à posse de si, à posse da individualidade durável e afirmada. (Bataille, 1987: 14)

$\mathrm{Na}$ obra de Nuno Ramos a linguagem aparece portanto constantemente tensionada, ela quer ir para além de si própria, quer evocar a força dos restos, em uma espécie de lamento contínuo por ser a palavra um distanciamento da natureza, uma espécie de clausura, mas que se lança em busca do oposto, seu potencial transgressor, erótico.

Se fosse possível, por exemplo, estudar as árvores numa língua feita de árvores, a terra numa língua feita de terra, se o peso do mármore fosse calculado em números de mármore, se descrevêssemos uma paisagem com a quantidade exata de elementos que a compõem, então estenderíamos a mão até o próximo 
corpo e saberíamos pelo tato seu nome e seu sentido, e seríamos deuses corpóreos, e a natureza seria nossa como uma gramática viva, um dicionário de musgo e de limo, um rio cuja foz fosse seu nome próprio. Mas é com nosso sopro que nos dirigimos a tudo, com a voz que o frágil fole da garganta emite, com o hálito que carrega nossas enzimas, é com o pequeno vento de nossa língua que chamamos o vento verdadeiro. Mais do que comer, correr ou flechar a carne alheia, mais do que aquecer a prole sobre a palha, nós nos sentamos e damos nomes, como pequenos imperadores do todo e de tudo. (Ramos, 2008: 19)

$\mathrm{Na}$ mesma medida, nota-se no filme de Claire Denis o uso do efeito bokeh, em cenas de pouca profundidade de campo. O desfoque é utilizado como elemento narrativo para destacar os personagens do espaço, desloca-los, suprimi-los. O recurso é portanto utilizado para criar um efeito de isolamento, clausura. A solidão dos personagens é então representada também em forma de lamento: ele quer "sair de si", quer habitar os espaços, quer alongar a profundidade de campo e misturar-se com os objetos. Todo o potencial erótico inibido dos personagens é então deslocado para a agressividade de suas ações, de seus movimentos, como na cena em que o personagem Boni, pizzaiolo, afunda seu rosto na massa de pizza, perfura a massa com os dedos, entra no corpo flácido do objeto que cede às suas investidas. Presente está o desejo de incorporar, o primitivismo (o tato, o cheiro, a visão), a bestialidade, próprios do erotismo.

Assim também se constrói a metáfora da boneca russa, presente na obra de Nuno Ramos, tal como quando o autor descreve o pó que recobre a pele. Refletindo sobre a existência de um corpo dentro do corpo, duas ideias antagônicas são expostas: de clausura e de expansão. Pois ao mesmo tempo em que esse personagem é construído em camadas, seu corpo é perturbado: o vento que toca a pele, o pó que recobre a pele, a carne, os ossos, a consciência. Onde estaria, afinal, o corpo de seu personagem?

Quem põe uma boneca russa dentro da outra é o dia. E quem põe um dia dentro do outro sou eu. Assim, eu e meus dias, como colecionadores, vamos escondendo 
bonecos iguais a nós mesmos, um dentro dos outros. (Ramos, 2008: 99)

Um outro ponto de escapamento do corpo, de libertação, presente em ambas as obras é própria metáfora do olhar. No filme de Claire Denis, a maneira de filmar as trocas de olhares separa os personagens em planos distintos. Assim, o efeito de troca de olhares é realizado sem que os dois interagentes em questão dividam o mesmo plano. Algo os separa, portanto: o limite do quadro. Um quer o outro, um deseja o outro, mas permanecem distantes pela maneira que se encaixam na cena.

Apenas na cena final do filme, Boni aparece dividindo o plano com um bebê recém-nascido, filho de sua irmã, Nenette. Enquanto trocam demorados olhares, a criança urina em seu peito. Boni sente o calor da urina a escorrer pelo seu corpo e sorri. A forma como a cena é filmada realça a interseção citada entre os conceitos de resto e de erotismo, com os dois personagens que trocam os olhares e se fundem no mesmo plano. Seus corpos se confundem, portanto, em cena, enquanto a urina - o resto em figura de linguagem - "liga" um corpo ao outro.

Outro ponto de relevância na cena é o fato do protagonista contracenar com um bebê, tão recém inserido na linguagem, tão anterior à linguagem. Esse estado primitivo é próprio da Experiência Interior - conceito batailleano que versa com o emudecimento da voz discursiva, da razão.

Si vivimos sin repulsa bajo la ley del lenguaje, estos estados están en nosotros como si no existiesen. Pero si chocamos contra tal ley, podemos, de pasada, detener la conciencia sobre uno de ellos $y$, haciendo callar en nosotros el discurso, detenemos en la sorpresa que nos proporciona. (Bataille: 1973: 24)

Em uma passagem semelhante na obra de Nuno Ramos, temos o personagem observando e tocando o corpo de sua mulher, enquanto ela dorme. $O$ interesse gerado pelo corpo adormecido nos dá a dimensão do primitivismo como via erótica. $O$ resto, afinal: sintomas de que um discurso não se completa. 
Nunca cansei de tocá-la quando dorme. Seu sono de alguma forma me dá medo. Não tanto porque se esqueça de mim (talvez nem dormindo se esqueça), mas, ao contrário, porque se oferece de um modo completo, parecendo inteiramente disponível. Meu desespero, a sentença de que vou perdê-la, não me abandona nunca, aumenta minha necessidade de tocá-la - agora que se separou do seu trajeto do dia, de seus deveres e interesses, de seu circuito de tarefas e está ali diante de mim, enroladinha no conforto de seu próprio corpo e dos lençóis que afasta com os pés. Agora, para mim, ela é aquilo que sempre deveria ter sido - um corpo livre, povoado por associações, desconectado da minúcia orçamentária da vida modorrenta, aberto à maré de suas ilusões, de seus medos, de seu passado e de seu futuro. (Ramos, 2008: 48)

As obras se ligam pela metáfora do corpo-sim, esculpida por Nuno Ramos. O corpo-sim é a expansão, ou como quer o autor: engordar, aumentar a superfície de contato com o mundo. O mesmo acontece no filme, onde os personagens vagam por uma cidade grande, Paris, esbarrando nos transeuntes, buscando algo dentro do outro que 0 desestabilize, a expansão, o corpo-sim. Em ambas as obras, o erotismo só encontra vazão no primitivismo, quando os personagens furam as paredes da linguagem, na experiência interior, através da própria imagem do desnudamento, dos sentidos. Os sons, os cheiros e as texturas são elementos estéticos centrais que nos dão essa dimensão: daqui a linguagem não passa.

Tudo quer nos contar a falta, o incompleto, seja quando Nuno Ramos interrompe seus relatos, transgredindo o próprio formato dos ensaios, para dar lugar às poesias, os Ós, seja quando Claire Denis fabrica suas imagens em uma teleobjetiva, aproximando o quadro da pele dos personagens, deixando sempre uma parte do corpo fora da tela. Resta o sentimento: algo não foi contado, algo não está ali. E como se uma ausência no coração de ambos os autores os despertassem para os espaços construídos, como se o intangível, indízível, fosse a própria força motriz de suas poesias, as obras se criam e se esculpem em um ambiente vazado, deixando sempre exposto o sentimento de que a 
ausência será sempre parte da presença. É ali que nós, espectadores ou leitores, podemos vazar.

Una sensibilidad llegada a ser desligamiento de lo que afecta a los sentidos tan interior que todos los retornos de lo exterior, el caer de una aguja, un crujido, tienen una inmensa y lejana resonancia... Los hindúes han advertido esta paradoja. Imagino que sucede como con la visión, que una dilactación de la pupila vuelve aguda en la oscuridad. Aquí la oscuridad no es la ausencia de luz (o de ruido), sino la absorción al exterior. En la simple noche, nuestra atención está entregada por completo al mundo de los objetos por la vía de las palabras, que persiste. El verdadero silencio tiene lugar en la ausencia de las palabras; que caiga una aguja entonces y me sobresalto como si hubiese sido un martillazo... En ese silencio hecho desde dentro, no es ya un órgano, es la sensibilidad entera, es el corazón, lo que se ha dilatado. (Bataille, 1973: 27)

\section{Referências}

Bataille, G. (1973). La experiencia interior. Madrid: Taurus Ediciones.

Bataille, G. (1987). O erotismo. Porto Alegre: L\&PM.

Blanchot, M. (2011). O espaço literário. Rio de Janeiro: Rocco.

Derrida, J. (1999). O Animal que logo sou. São Paulo: UNESP.

Nancy, J. (2000). Corpus. Lisboa: Vega.

Nancy, J. (2006). El Intruso. Buenos Aires: Amorrortu.

Nancy, J (2014). Embriaguez. Lanús: Ediciones La Cebra.

Nietzsche, F. (2008). A vontade de poder. Rio de Janeiro:

Contraponto.

Nietzsche, F. (1995) Ecce homo, como alguém se torna o que é. São

Paulo: Companhia das Letras.

Ramos, N. (2008). Ó. São Paulo: lluminuras. 